\title{
Cognitive impairment in OCD patients - an exploratory study
}

\author{
Pankaj Kumar ${ }^{1}$, Rupesh Chaudhry ${ }^{2}$, B.P. Mishra ${ }^{3}$ \\ ${ }^{1}$ Assistant Professor, Department of Psychiatry \\ ${ }^{2}$ Professor, Department of Psychiatry \\ ${ }^{3}$ Professor of Clinical Psychology, Department of Psychiatry \\ Dayanand Medical College and Hospital, Ludhiana, Punjab.
}

Corresponding author: Rupesh Chaudhry

Email-rupeshchaudhry123@yahoo.co.in

\begin{abstract}
Background and Objectives: OCD is one of the most debilitating psychiatric conditions with complex etiopathological profile causing interference with a wide range of social and cognitive demands. NeuroPsychological and neuro-imaging studies on OCD patients have implicated that the frontal cortex and subcortical structures are involved in this disorder and testing has revealed evidence of impairment in visuospatial abilities, non-verbal memory and executive function. To evaluate cognitive impairment in Obsessive Compulsive Disorder patients.

Methods: Thirty patients who presented to Psychiatry Department of Dayanand Medical College and Hospital, Ludhiana with diagnosis of OCD as per ICD-10 were taken up for the study. Cognitive impairment was assessed using PGI brain dysfunction battery designed for Indian population by Dwarka Pershad and Santosh K. Verma ( $3^{\text {rd }}$ edition 2015). PGI brain dysfunction battery is a measure of cognitive impairment consisting of: Verbal Adult intelligence scale, Revised Bhatia short battery of performance tests of intelligence, PGI memory scale, Nahor Benson test, Bender Visuo-Motor Gestalt test. Those patients who had any major medical disorder or any other Psychiatry disorder on AXIS-I were excluded from the study. Results: In the present study, dysfunction was noticed in areas of immediate recall ,abstract thinking, arithmetical ability in verbal intelligence subscale and in visuo-motor coordination. These all areas are executive functions of frontal lobe. This shows that OCD patients are having difficulty in calculations due to interference of the obsessive symptoms, though their attention and concentration were found intact. Visuo-motor coordination problem may be due to compulsive tendency due to which overlap, perseveration and partial rotation were found dysfunctional.

Conclusion: Since OCD is highly distressing to the patient, the superadded cognitive dysfunctions such as memory impairment, abstract thinking, impairment in visuo-motor coordination further worsens the outcome of the illness. So, early identification of these dysfunctions would provide considerable benefit to the patients.
\end{abstract}

Keywords: Obsessive compulsive disorder, cognition, executive functioning.

(Paper received $-9^{\text {th }}$ October 2018, Peer review completed $-20^{\text {th }}$ November 2018)

(Accepted $-24^{\text {th }}$ November 2018)

\section{INTRODUCTION}

Obsessive Compulsive Disorder (OCD) is one of the most debilitating psychiatric conditions which complex etio-pathological profile cause interference with a wide range of social and cognitive demands [1]. OCD has emerged as fine most prominent mental disorders associated with greatest worldwide disability because of the increasing awareness regarding cognitive impairment in OCD. Brain regions implicated to be involved in pathogenesis of OCD are orbitofrontal cortex, anterior cingulated cortex, basal ganglion, thalamus and 
some limbic structures [2]. There is a range of evidence that cortico-striatal thalamic cortical system (CSTC) is disrupted in OCD. CSTC plays a crucial role in the implicit learning of procedural strategies, and their subsequent automatic execution. Neuropsychological testing shows that there is impairment in visuo-spatial abilities [3], non-verbal memory [4] and executants functioning [5]. Poor decision making and mental flexibility [6]. Executive function deficits in OCD are linked to poor decision-making processes related to orbito-frontal cortex. Many studies have documented a correlation between OCD and spatial working memory particularly for difficult task. Most of the studies regarding cognitive functioning impairment are done in west and limited data is available in India so the present study was planned to find the different domains of cognition which are affected in OCD. The study was aimed at evaluating cognitive impairment in patients with $O C D$.

\section{METHODOLOGY}

A total of 50 patients who presented to Psychiatry Department of Dayanand Medical College and Hospital, Ludhiana with diagnosis of OCD as per ICD-10 were taken up for the study after obtaining the informed consent. Cognitive impairment was assessed using PGI brain dysfunction battery designed for Indian population by Dwarka Pershad and Santosh K. Verma ( $3^{\text {rd }}$ edition 2015). PGI brain dysfunction battery is a measure of cognitive impairment consisting of: Verbal Adult intelligence scale, Revised Bhatia short battery of performance tests of intelligence, PGI memory scale, Nahor Benson test, Bender Visuo-Motor Gestalt test. Those patients who had any major medical disorder or any other Psychiatry disorder on AXIS-I were excluded from the study. Total time taken is approximately two hours.

Parameters taken for analysis:

1. socio-demographic data

2. cognitive functioning

\section{RESULTS}

Table 1 - Socio-demographic data

\begin{tabular}{|l|l|c|}
\hline AGE (years) & N-50 & $14 \%$ \\
\hline Up to 30 & 7 & $54 \%$ \\
\hline $\mathbf{3 1 - 4 0}$ & 27 & $12 \%$ \\
\hline $\mathbf{4 1 - 5 0}$ & 6 & $20 \%$ \\
\hline$>\mathbf{5 1}$ & 10 & $66 \%$ \\
\hline EDUCATION & $20 \%$ \\
\hline Up to matric & \multicolumn{1}{|c|}{33} & $14 \%$ \\
\hline Matric to graduation 10 & \\
\hline Post-graduation & 7 &
\end{tabular}

\section{DISCUSSION}

In socio demographic profile, most of the patients were in the age group between 31-40 (54\%) and majority of them were educated up to matric $(66 \%)$. In the present study the most common dysfunction was found in arithmetic ability parameter $70 \%$. Such kind of patients shows more confusion and inability to calculate. It may be due to symptoms of OCD where patient is indecisive. This further lead to inability to meet responsibilities of their day to day life. Literature also supports this fact that OCD patients have impaired memory, poor recall and impairment in retrieving autobiographical memories [7-8]. Significant dysfunction was observed on visuo- motor co-ordination on Bender Visuo- motor coordination test and Nahar Benson Test (30\% each) which reflects difficulty in performing motor activities comfortably in day to day activity. 
Table 2 - Cognitive impairment in patients with OCD

\begin{tabular}{|l|r|r|}
\hline VARIABLE & Score & \multicolumn{1}{l|}{ percentage } \\
\hline REMOTE Memory & 0 & $0 \%$ \\
\hline RECENT Memory & 0 & $0 \%$ \\
\hline MENTAL Balance & 0 & $0 \%$ \\
\hline Attention and concentration & 0 & $0 \%$ \\
\hline Delayed Recall & 0 & $0 \%$ \\
\hline Immediate Recall & 6 & $20 \%$ \\
\hline Retention of SIMILAR pairs & 6 & $20 \%$ \\
\hline Retention of DISSIMLAR pairs & 0 & $0 \%$ \\
\hline Visual Retention & 0 & $0 \%$ \\
\hline Recognition & 0 & $0 \%$ \\
\hline P/K X100 & 3 & $10 \%$ \\
\hline PERFORMANCE Quotient & 12 & $40 \%$ \\
\hline T.Q on information & 6 & $20 \%$ \\
\hline T.Q on digit span & 3 & $10 \%$ \\
\hline T.Q on arithmetic & 21 & $70 \%$ \\
\hline T.Q on comprehension & 0 & $0 \%$ \\
\hline Performance Quotient -Verbal Quotient & 6 & $20 \%$ \\
\hline Nahor-Benson test & 9 & $30 \%$ \\
\hline Bender -Gestalt test & 9 & $30 \%$ \\
\hline
\end{tabular}

This may be due to compulsive acts which the patient shows in their routine functioning. They were also showing significant difficulty in memory functioning in areas of immediate recall and retention of similar pairs ( $20 \%$ each). The literature also responds that significant Neuropsychological deficits in OCD consists primarily of executive deficits [9], involving frontal striatal system dysfunction [10], impairment in visuospatial abilities and non-verbal memory [11-12].

Literature also showed specific cognitive deficits on tasks of executive and visual motor functions which are similar to performance of patients with frontal lobe excision and sub cortical pathology suggesting that the underlying dysfunction of frontal striatal system [13].

The above findings emphasize the need of comprehensive guidelines including pharmacological psychosocial management and family therapy to cover the entire spectrum of dysfunction in OCD patients.

\section{CONCLUSION}

Since peak of responsibilities are at age range of 30-40 years and due to illness, the suffer is not able to meet their responsibilities leads to additional enhancement in anxiety and frustration with the treatment process leading to possibility of relapses, dissatisfaction with the treatment process, drop outs and resistance to treatment leading to further morbidity.

\section{REFERENCES}

1. Lucey JV, Burness CE, Costa DC, Gacinovic S, Pilowsky LS, Ell PJ. Wisconsin Card Sorting Task (WCST) errors and cerebral flow in obsessive-compulsive disorder (OCD), Br J Med Psychol 1997;70(4):403-11.

2. Anderson KE, Savage CR. Cognitive and neurobiological findings in obsessive-compulsive disorder. Psychiatr Clin North Am 2004;27:37-47.

3. Hollander E, Cohen L, Richards M, Mullen L, DeCaria C, Stern Y. A pilot study of the neuropsychology of obsessive-compulsive disorder and Parkinson's disease: Basal ganglia disorders. J Neuropsychiatry Clin Neurosci 1993;5:104-7.

4. Christensen KJ, KimSW, Dysken MW, Hoover KM. Nueropsychological performance in obsessivecompulsive disorder. Biol Psychiatry 1992:31:4-18. 
5. Rubin RT, Villanueva-Meyer J, Ananth J, Trajmer PG and Mena I. Regional 133XE cerebral blood flow and cerebral HMPAO uptake in unmedicated OCD patients and matched normal control subjcts: determination by high resolution single photon emission CT. Arch Gen Psychiatry 1992;49:695-702.

6. Cavedini, P, Zorzi, C, Piccinni, M, Cavallini, MC, Bellodi, L. Executive dysfunctions in obsessivecompulsive patients and unaffected relatives: searching for a new intermediate phenotype. Biol Psychiatry 2010;67:1178-84.

7. Wilhelm S,RJ McNally, L Baer. Autobiographical memory in obsessive compulsive disorder ; Br J Clin Psychol 1997;36(1):21-31.

8. Sher KJ, Frost RO, Kushnee M, Crews TM, Alexander JE. Memory deficit in compulsive checkers; replication and extension in clinical sample. Behav Res Ther 1989;27(1):65-9.

9. Abramovitch A, Dar R, Schweiger A, Hermesh H. Neuropsychological impairments and their association with obsessive compulsive symptom severity in obsessive compulsive disorder. Arch Clin Neuropsychol 2011; 26(4):364-76.

10. Schmidtke K, Schorb A, Winkelmann G. Cognitive frontal lobe dysfunction in obsessive-compulsive disorder. Biol Psychiatry 1998;43(9): 666-73.

11. Savage CR, Keuthen NJ, Jenike MA, Brown HD, Baer L, Kendrick AD, et al. Recall and recognition memory in obsessive-compulsive disorder. J Neuropsychiatry Clin Neurosci 1996;8:99-103.

12. Van der Wee NJ., Ramsey NF., Jansma JM., Denys Da, van Megen HJ., Westenberg HM \& Khan RS. Spatial working memory deficits in obsessive compulsive disorder are associated with excessive engagement of the medial frontal cortex: Neruolmag 2003;20(4):2271-80.

13. Rosemary P, Paul M, Michael K, Christos P. Cognitive deficits in obsessive compulsive disorder on tests of frontal striatal function. Biol Psychiatry 1998;43(5):348-57.

$* * * * * * * * * * * * * * * * * * * * * * * * * * * * * * * * * * * *$

$$
\begin{gathered}
\text { Acknowledgements - Nil } \\
\text { Conflict of Interest - Nil } \\
\text { Funding - Nil }
\end{gathered}
$$

